\title{
Recurso digital para apoio ao aprendizado de Biologia Celular e Tecidual
}

\author{
Tatiana Montanari, Departamento de Ciências Morfológicas, ICBS, UFRGS, \\ t.montanari@bol.com.br \\ Maria Isabel Timm, Centro Nacional de Supercomputação, UFRGS, \\ beta@cesup.ufrgs.br \\ Gabriela Trindade Perry, Programa de Pós-Graduação em Informática na Educação, \\ UFRGS, gabrielaperry@ hotmail.com \\ Leonardo Lisbôa da Motta, curso de Graduação de Ciências Biológicas, UFRGS, \\ leomotta.poa@terra.com.br \\ Sofia Louise Santin Barilli, curso de Graduação em Enfermagem, UFRGS, \\ sofiabarilli@gmail.com
}

Resumo: É apresentado o processo de elaboração de um Atlas digital para ser usado como apoio didático-pedagógico pelos alunos das disciplinas de Biologia Celular e Tecidual (Histologia) dos cursos das Ciências Biológicas e da Saúde, em aulas convencionais, no estudo extra-classe ou em cursos à distância. $\mathrm{O}$ Atlas contém fotografias de células e seus constituintes, dos tecidos e dos órgãos. As imagens foram obtidas ao microscópio de luz ou eletrônico de preparados usados nas aulas práticas ou de material de pesquisa. São acompanhadas de legendas explicativas e podem ser acessadas pelos tópicos do conteúdo (célula - tecidos - sistemas), por busca por palavra e de uma lista geral das imagens disponíveis. A concepção pedagógica do Atlas foi baseada na descrição da inteligência naturalista, um tipo de processamento de informações fundamentado sobre o reconhecimento e a categorização de espécies, necessário a alunos e profissionais da área de Biologia. Ambas as atividades cognitivas viabilizam, no caso do Atlas, a identificação visual e a associação entre a morfologia e a função das células, dos tecidos e dos órgãos. No planejamento do Atlas, foram privilegiadas as possibilidades de visualização e comparação, a partir das quais serão desenvolvidas atividades pedagógicas.

Palavras-chave: biologia celular, objeto de aprendizagem, informática na educação, ensino de ciência e tecnologia, tecnologia educacional.

\section{Título em inglês: Digital resource to support the learning of Histology and Cell Biology}

Abstract: It is presented the construction process of a digital atlas, to be used as pedagogical support for students of Cell Biology and Histology from Health and

Biological Sciences courses, in their regular and extra class activities and distance education courses. The atlas has photographs on cell and its components, tissues and organs. The images were obtained from practical classes or research material for light and electronic microscopy. They have explanatory legends and can be accessed by category (cell - tissues system), from word search and from a list of available images. The pedagogical conception of the atlas was based on the description of the naturalist intelligence, a kind of information processing based on recognition and categorization of specimens, necessary for students and professionals of the biological field. Both cognitive activities together in the atlas will make it possible the visual identification and association between the morphology and the function of the cells, tissues and organs. During the atlas planning, visualization and comparison capabilities were emphasized and from them pedagogical activities will be further developed.

Keywords: cell biology, learning object, informatics on education, science and technology teaching, educational technology. 


\section{Introdução}

A célula é a unidade estrutural e funcional básica dos seres vivos. As células organizam-se em tecidos, e estes, em órgãos e sistemas. A Biologia Celular preocupa-se com a compreensão da célula quanto aos seus constituintes e à sua atividade funcional, e a Biologia Tecidual (ou Histologia) estuda os tecidos e os sistemas do organismo (De Robertis e Hib, 2001; Montanari, 2006; Carvalho e Recco-Pimentel, 2007). Na Universidade Federal do Rio Grande do Sul, essas disciplinas são ministradas pelo

Departamento de Ciências Morfológicas, do Instituto de Ciências Básicas da Saúde (ICBS), para vários cursos das Ciências Biológicas e da Saúde, justificando-se sua importância no ensino de Graduação pelo papel-chave que desempenham na pesquisa biomédica.

O projeto do Atlas, que ainda está em estágio inicialı, pretende ser um instrumento de apoio didático-pedagógico a esses alunos tanto em sala de aula como no estudo extraclasse. Poderá ainda ser utilizado pelos alunos do curso de Licenciatura em Biologia à distância, recentemente criado, e pela população acadêmica de outras Universidades. Além disso, sua produção cumpre a função de integrar o ensino de Ciências Biológicas na nova cultura tecnológica educacional e, dentro dela, apoiar a reflexão sobre as características do processo de ensino-aprendizagem específicos desta área, buscando entender quais são os possíveis impactos cognitivos, tanto para os alunos quanto para o trabalho dos professores. As principais características desta nova tecnologia são o fácil acesso, via Internet, o potencial de representação em múltiplos formatos, a hipertextualidade (acesso a informações interconectadas) e a interatividade.

Buscou-se potencializar esses recursos, a partir da compreensão das necessidades do aluno da área, tendo-se como base a Teoria das Inteligências Múltiplas, de Gardner (2001) e, em particular, as definições propostas pelo autor para o que seria o tipo de inteligência prevalente em indivíduos inclinados para as Ciências Biológicas: a inteligência naturalista, descrita a seguir.

Howard Gardner, psicólogo norte-americano, desenvolveu, em 1992, um modelo múltiplo de funcionamento da inteligência humana, por discordar das mensurações generalistas do nível de inteligência dos indivíduos. O autor questionava os testes de QI (quociente de inteligência) que predominavam no início do século XX, relacionando a idade mental à idade cronológica dos indivíduos, e as interpretações sobre raças e inteligência, nitidamente preconceituosas.

Segundo suas observações, com base no acompanhamento de atividades neuropsíquicas após lesões de áreas específicas do cérebro, os indivíduos apresentam capacidades, habilidades e talentos diferenciados. Gardner entendeu que há um grande leque de possibilidades de aquisição e processamento de informação e, portanto, de formas de estruturação de conhecimento. Seu ponto de partida é a modularidade da mente humana, ou a idéia de que esta pode ser descrita mais como uma série de "faculdades relativamente independentes, tendo relações apenas frouxas e não

$1 \mathrm{O}$ projeto foi iniciado cerca de três meses antes da produção deste artigo, não sendo possível apresentar resultados de utilização junto aos alunos, de forma a testar a funcionalidade do Atlas e, principalmente, a sua adequação à intenção didático-pedagógica formulada com base na bibliografia proposta. Considerouse importante, entretanto, descrever a idéia, como forma de documentar o processo e estimular outros professores desta área, pouco envolvidos com a produção de tecnologia educacional, a refletir sobre as possibilidades das novas tecnologias, atendendo inclusive à intenção do Edital da UFRGS que o viabilizou. 
previsíveis umas com as outras, do que como uma máquina única para todas as coisas, com uma capacidade de desempenho constante, independente de conteúdo e contexto" (Gardner, 2001, p. 45).

Originalmente, na época do desenvolvimento da Teoria, o autor identificou sete tipos principais de inteligência, cada uma das quais relacionadas a uma área de atividade ou do conhecimento humano, ou, possivelmente, a inclinações profissionais específicas, pela identificação com uma ou outra forma de pensar e agir, embora, como bem lembre o autor, todas as formas de inteligência possam estar presentes em todas as áreas. São elas: inteligência lingüística, matemática, musical, físico-cinestésica, espacial, interpessoal e intrapessoal. Ao revisar a Teoria, 20 anos após sua apresentação, Gardner sugeriu três novas categorias de inteligência: existencial, espiritual e naturalista. A última destas categorias refere-se ao que seria o tipo de processamento cognitivo característico dos alunos e profissionais da área de Ciências Biológicas.

"Um naturalista demonstra grande experiência no reconhecimento e na classificação de numerosas espécies - a flora e a fauna - de seu meio ambiente" (Gardner, 2001, p. 64), escreve o autor, chamando atenção ainda para a importância desses profissionais, em todas as culturas, para categorizar organismos novos e desconhecidos, estabelecendo taxonomias e critérios de valor ou perigo, em relação a cada espécie. Uma tal habilidade tão característica, diz ainda, seria um aprimoramento da capacidade geral da inteligência humana, de reconhecimento e classificação de objetos, e se expande para além da capacidade visual, podendo ser transferido inclusive ao tato, no caso de indivíduos cegos. "As biografias dos biólogos costumam documentar um fascínio precoce por plantas e animais e um impulso para identificar, classificar e interagir com estes seres: Darwin, Gould e Wilson são apenas os mais em evidência desse grupo", diz Gardner (2001, p. 67). Se, enquanto característica geral da espécie, este tipo de inteligência pode ser considerado inato, ou intuitivo, mesmo em crianças, vai exigir aprendizado e disciplina, quando aparecer estruturada na forma de matérias, como a botânica ou a entomologia, citadas pelo autor, ou a biologia celular e tecidual, no caso do público-alvo do Atlas digital produzido.

\section{Material e métodos}

O objeto de aprendizagem consiste em um Atlas digital de Biologia Celular e Tecidual com fotografias de células e seus constituintes, bem como dos tecidos e dos órgãos formados pelas células. As imagens foram obtidas ao microscópio de luz e ao microscópio eletrônico de preparados usados nas aulas práticas ou de material de pesquisa. O Atlas está sendo desenvolvido com uso do software Macromedia Flash, visando oferecer navegação amigável e intuitiva. O conteúdo está organizado nos seguintes tópicos: 1) Célula: Morfologia celular, Membrana plasmática, Citoesqueleto, Organelas, Ciclo celular e Matriz extracelular; 2) Tecidos: Tecidos Epitelial, Conjuntivo, Muscular e Nervoso, e 3) Sistemas: Sistemas Circulatório, Linfático, Digestório, Respiratório, Urinário e Tegumentar.

Parte do acervo fotográfico já foi digitalizado, encontrando-se o projeto, no momento, em fase de alimentação do sistema com as fotos. As imagens são acompanhadas de legendas explicativas e poderão ser acessadas a partir dos itens do conteúdo (células tecidos - sistemas), disponíveis de qualquer tela do sistema, de busca por palavra e de uma lista geral das imagens disponíveis. Está sendo desenvolvida ferramenta de comparação entre imagens, as quais podem ser escolhidas na lista geral e arrastadas a uma interface de visualização. O Atlas será disponibilizado para acesso via Internet, na home-page do ICBS, 
com acesso também desde o repositório Cesta, do CINTED1. Serão desenvolvidas estratégias pedagógicas para seu uso, de forma a oferecer desafios interativos aos alunos, em atividades presenciais, ou em experimentos de uso remoto e aprendizado autônomo, através da Plataforma Moodle hospedada no CESUP-UFRGS.

\section{Resultados e discussão}

O Atlas digital de Biologia Celular e Tecidual está sendo elaborado para, primeiramente, permitir a visualização de imagens obtidas ao microscópio de luz e ao microscópio eletrônico de células e seus constituintes, dos tecidos e dos órgãos, acompanhadas das respectivas legendas, utilizando uma estrutura interativa e amigável de navegação hipertextual. Este recurso, por si, agrega valor ao trabalho acadêmico, por caracterizar uma importante documentação de imagens, digitalizadas a partir de material das aulas práticas e de pesquisa. A excelência das imagens virtuais permite ainda a reprodução rigorosa da informação visual das lâminas histológicas, facilitando o acesso do aluno mesmo extra-classe, a qualquer tempo. A navegação hipertextual e interativa, possibilita o acesso às imagens, de forma rápida, de qualquer lugar do ambiente, o que foi potencializado por ferramentas de busca por palavra e de uma relação do conjunto geral das imagens disponíveis.

Complementando a função de apoio cognitiva do Atlas, está sendo desenvolvida ferramenta de comparação entre imagens, as quais podem ser escolhidas na lista geral e arrastadas a uma interface de visualização. Com este recurso, espera-se atender à necessidade de aprendizado dos estudantes das áreas biológicas, que necessitam exercitar a atenção para a comparação entre o aspecto morfológico e a atividade funcional das células, dos tecidos ou dos órgãos. Com isso, atende-se ao que seria o aprendizado da atividade de categorização, que compõe o conjunto das principais características da inteligência naturalista, proposta por Gardner (2001). Compreender diferenças e semelhanças é a base do processo mental de categorização e será a base das atividades pedagógicas propostas aos alunos, para uso presencial e à distância, com a facilidade de que terão as imagens lado a lado, para facilitar esta conscientização.

O suporte facilitado ao acesso às imagens de forma interativa (através de menus, busca por palavras e da lista de imagens, conforme descrito anteriormente) e a possibilidade de compará-las seria o primeiro passo para apoiar a aquisição da habilidade de reconhecer o objeto em estudo, dentro da inteligência naturalista. A complementação pedagógica desta atividade, em fase de planejamento, será o desenvolvimento de desafios que levem o aluno a conscientizarem-se das diferenças/semelhanças entre as características morfológicas das células, bem como sua relação com a respectiva função. Para tanto serão desenvolvidas questões disponibilizadas aos alunos através de uma plataforma de ensino (Moodle) e resolvidas com o auxílio do Atlas.

Sugere-se que esta pesquisa seja ampliada futuramente, avaliando-se o impacto da tecnologia educacional virtual na facilidade de reconhecer visualmente os objetos apresentados, reter informações e detalhes característicos, de forma a poder relacioná-los com suas respectivas funções nos órgãos e sistemas.

As Figuras 1 a 3 ilustram algumas telas do Atlas. 


\section{Atlas Digital de Biologia Celular}

Tatiana Montanari - ICBS - UFRGS

Celula Tecidos Sistemas Lista de Imagens Compararimagens Busca Idioma

Apresentação: Este Atlas foi desenvolvido para ser um instrumento de consulta e objeto de aprendizagem para alunos das disciplinas de Biologia Celular e Tecidual (Histologia) dos cursos de graduação nas áreas das Ciências Biológicas e da Saúde.

Conteúdo: Fotografias de células e seus constituintes, dos tecidos e dos sistemas, obtidas em microscopia de luz ou eletrônica, săo apresentadas com as respectivas legendas, onde são incluídos o método de coloração e a ampliação da imagem para visualização em 1024 x 768 (resolução recomendada).

Fontes: Algumas fotomicrografias foram realizadas na própria UFRGS, a partir de material das aulas práticas. Outras imagens procedem de trabalhos de pesquisa.

Acessos: As consultas podem ser feitas por itens do conteúdo: células - tecidos - sistemas, e seus respectivos tópicos, disponiveis de qualquer tela do sistema. Também podem ser feitas buscas por palavra e a partir de uma lista geral de todas as imagens disponíveis. É possível ainda "comparar imagens", arrastando as imagens desejadas para que fiquem lado a lado, para melhor compreender semelhanças e diferenças, bem como sua relação com as respectivas funções da célula.

EQUIPE:

Autora: Profa. Dra. Tatia Montanari - Departamento de Ciências Morfológicas - Instituto de Ciências Básicas da Saúde (ICBS) - UFRGS

Coordenação: Jornalista Dra. Maria Isabel Timm - Centro de Supercomputaçăo (CESUP) UFRGS

Design: Msc. Gabriela Trindade Perry - Programa de Pós Graduação em Informática na Educação (PPGIE) - UFRGS

Bolsista SEAD: Leonardo Lisbôa da Motta - Ciências Biológicas - UFRGS

Digitalizaçāo: Sofia Louise Santin Barilli e Tatiana Montanari

Fotografias: Tatiana Montanari, Griscelda da Conceiçăo da Silva, Thaís de Oliveira

Plá, Daiene Tórgo Fabretti e Marta Silvana da Motta

Figura 1 - Tela de apresentação.

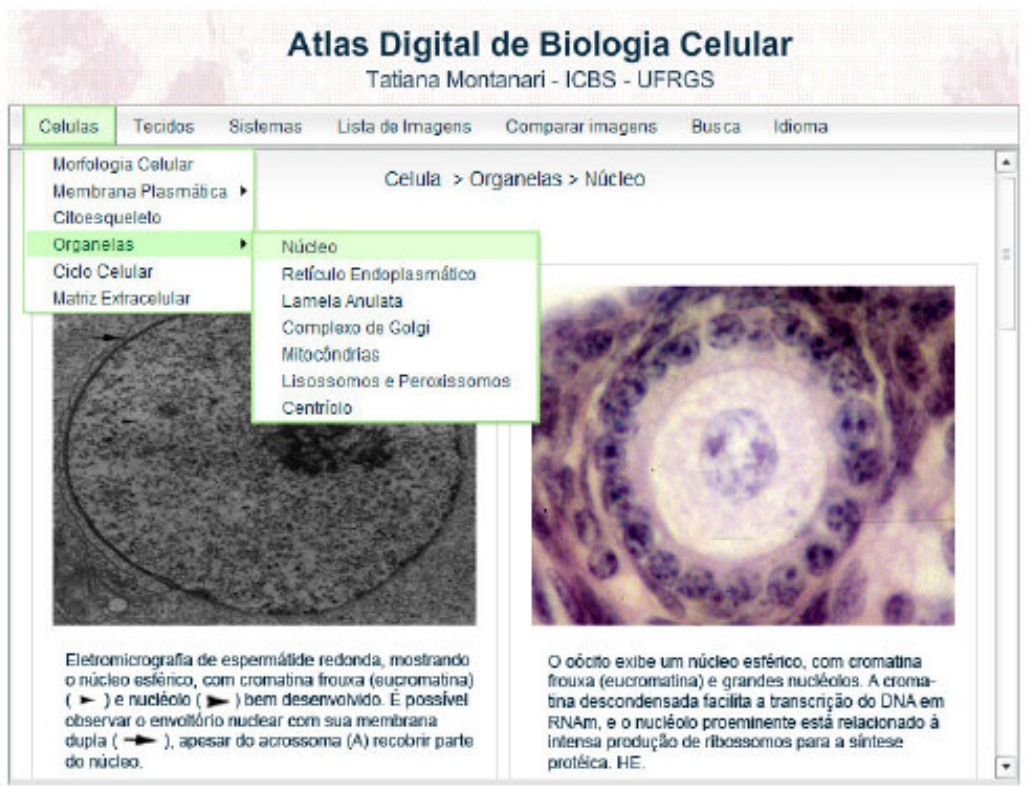

Figura 2 - Tela de navegação: página do conteúdo de células - organelas - Núcleo. A informação sobre a localização do visitante (em qual seção ele se encontra) está sempre disponível. 


\section{Atlas Digital de Biologia Celular}

Tatiana Montanari - ICBS - UFRGS

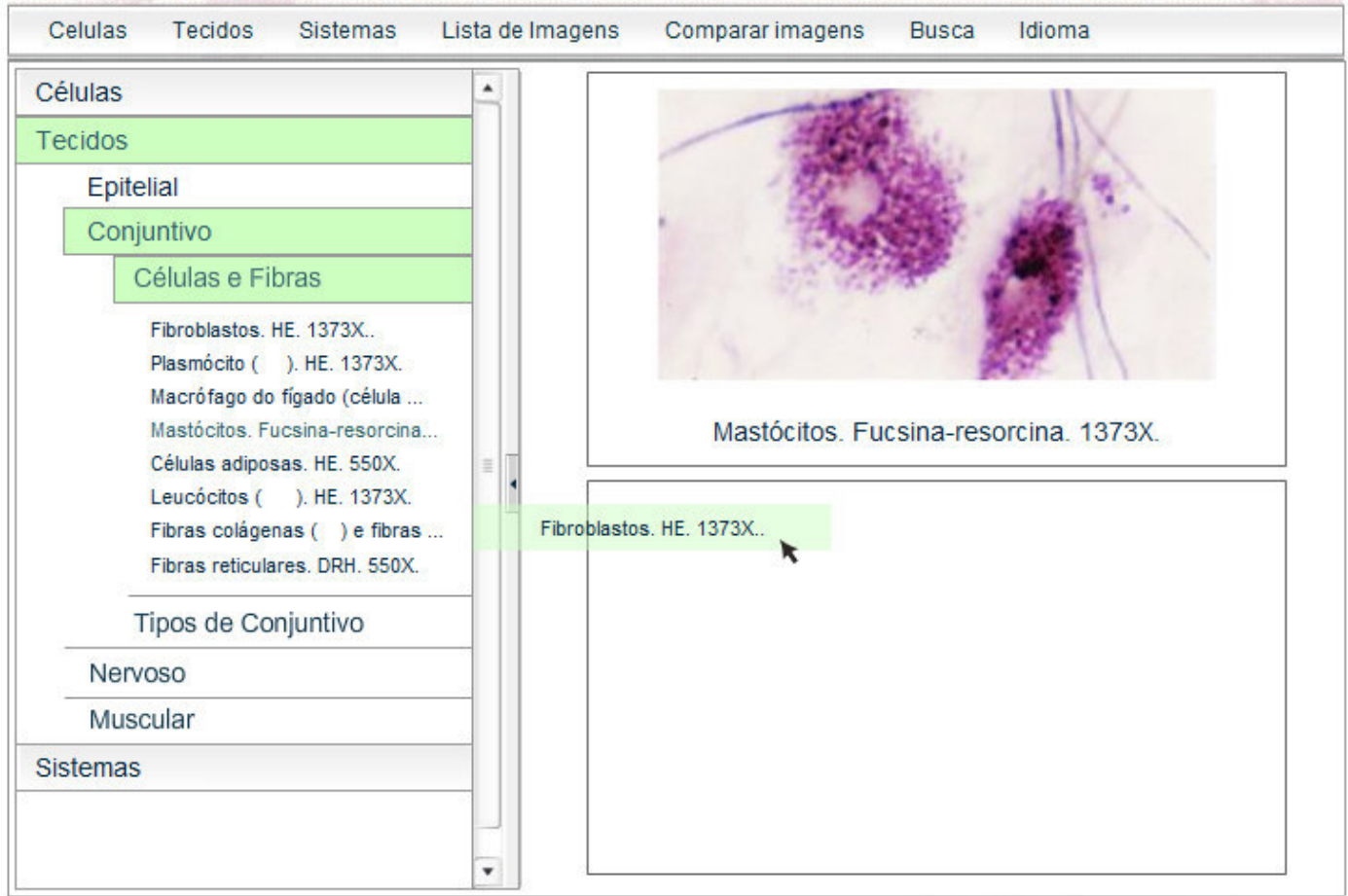

Figura 2 - Tela de navegação: página do conteúdo de células - organelas - Núcleo. A informação sobre a localização do visitante (em qual seção ele se encontra) está sempre disponível.

\section{Atlas Digital de Biologia Celular}

Tatiana Montanari - ICBS - UFRGS

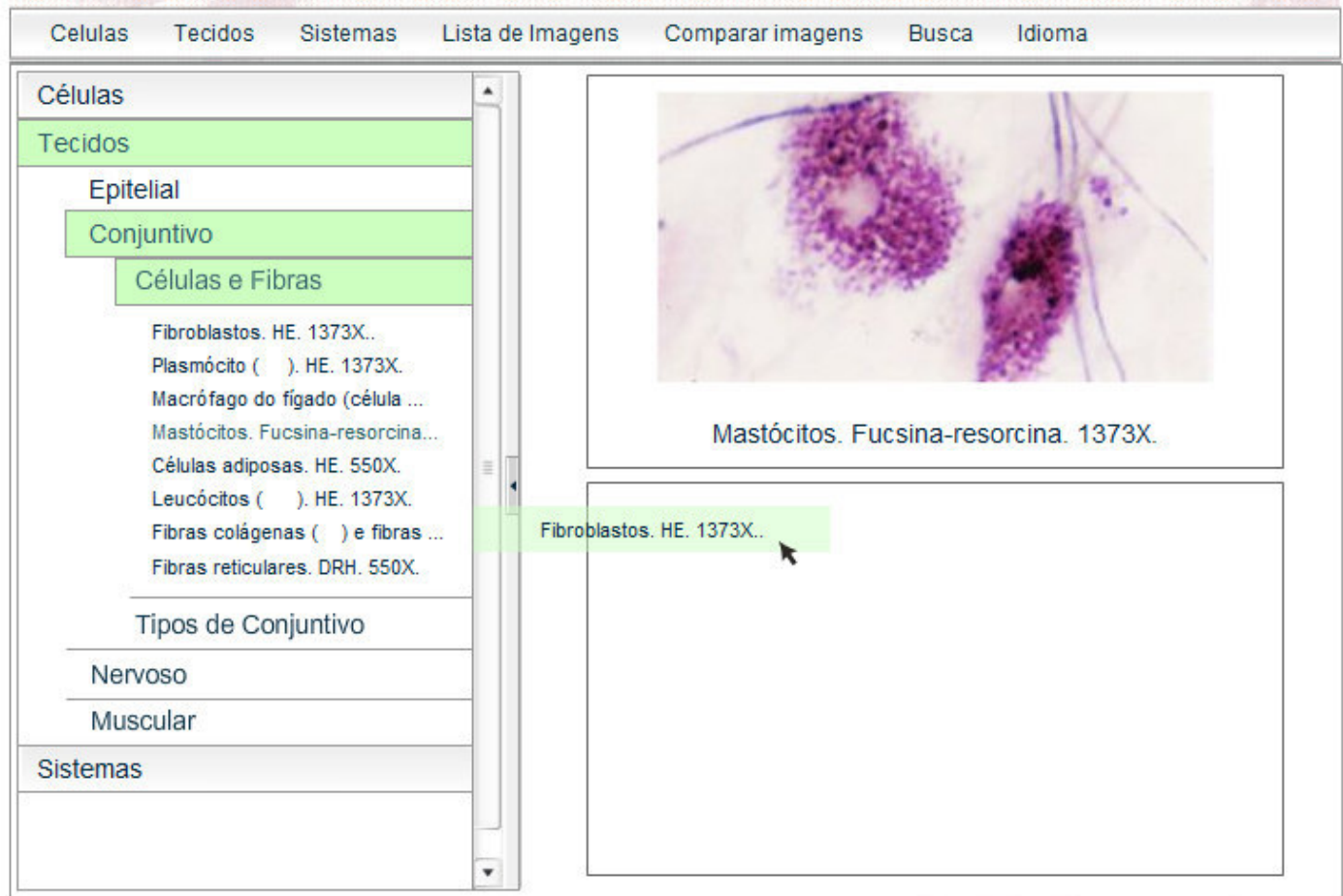


Figura 3 - Tela de comparação. O visitante pode escolher entre duas imagens de qualquer seção (sendo apenas as legendas exibidas na área à esquerda), e arrastá-la para a área à direita.

\section{Conclusões}

O trabalho apresentado é fruto de um projeto que contempla a produção de material didático-pedagógico virtual e, simultaneamente, a reflexão sobre as necessidades de qualificação do ensino de Ciências Biológicas. Ambas as atividades encontram-se em fase inicial, tanto no que se refere ao estudo das potencialidades dos recursos informatizados de representação e disponibilização de informações, quanto à pesquisa de instrumentos teóricos para dar suporte à pesquisa e prática educacional apoiada por tais artefatos. O Atlas deverá ser objeto de experimentação, nestas duas áreas, nas próximas etapas do projeto, quando poderá, então, contribuir efetivamente para a discussão sobre o uso de tecnologia educacional informatizada no ensino das Ciências Biológicas.

Em relação ao estudo das potencialidades dos artefatos informatizados como apoiadores do ensino e da aprendizagem, procurou-se usar dos recursos visuais aliados à interatividade. A informação visual, no caso do estudo da Biologia Celular e Tecidual é da maior importância, sendo este o motivo da priorização das imagens sobre qualquer outro tipo de informação no design do Atlas. Também por isto procurou-se facilitar a máximo o acesso a tais imagens, através de sua organização em categorias reconhecidas pelos membros da comunidade das Ciências Biológicas. Em relação à ferramenta "Lista de Imagem", a intenção é fornecer ao usuário uma lista dos dados contidos no Atlas, bem como o agrupamento dos dados dentro de cada categoria. Este recurso, aliado à distribuição das categorias em menus, incentiva a fixação da informação, através do uso e visualização repetidas, das categorias nas quais se distribuem as imagens. A "Busca por Palavras" é uma forma de contemplar: (1) o usuário que deseja acesso rápido a uma imagem em particular; (2) o usuário que deseja explorar o agrupamento das imagens dentro das categorias, já que, ao encontrar imagens cuja legenda contenha as palavras usadas na busca, será indicada a categoria à qual a imagem pertence (por exemplo: Sistemas > Sistema Circulatório); e (3) o usuário que deseja saber se há uma imagem cuja legenda contenha as palavras usadas na busca. Já a ferramenta de "Comparar Imagens" é uma forma explícita de incentivar a discriminação e reconhecimento de semelhanças e diferenças entre duas imagens, e relacioná-las relação com a função das células.

Em relação à pesquisa de instrumentos teóricos para dar suporte à pesquisa e prática educacional apoiada por artefatos informatizados, foram utilizados os conceitos apresentados por Gardner, em relação à existência de múltiplas formas de inteligência.

Esta hipótese fundamentou o projeto visual deste Atlas, e servirá de suporte para o planejamento das atividades a serem disponibilizadas aos estudantes através da plataforma Moodle.

\section{Notas do texto}

1 Atualmente, o projeto está em fase experimental, sem acesso externo ao Atlas. Futuramente, estará acessível através da home-page do ICBS (www.icbs.ufrgs.br) e do projeto CESTA - Coletânea de Entidades de Suporte ao uso de Tecnologia na Aprendizagem, é o repositório de objetos educacionais do CINTED - Centro Interdisciplinar de Novas Tecnologias Educacionais, da UFRGS (http://www.cinted.ufrgs.br/CESTA/cestadescr.html).

\section{Agradecimentos}


À Secretaria de Educação à Distância (SEAD) da UFRGS pelo apoio ao desenvolvimento deste Atlas através da bolsa ao acadêmico Leonardo Lisbôa da Motta.

Ao CESUP/UFRGS pelo apoio tecnológico.

Referências bibliográficas

CARVALHO, Hernandes Faustino; Recco-Pimentel, Shirley Maria. Célula. 2001. 1. ed. São Paulo: Manole, 2001. v. 1. 289 p.

De ROBERTIS, Eduardo M.F.; HIB, Jose. De Robertis Bases da Biologia celular e molecular. 3.ed. Rio de Janeiro: Guanabara Koogan, 2001. 418p.

- GARDNER, Howard. Mentes que mudam. Bookman / Artmed, Porto Alegre, 2005, 229p.

- GARDNER, Howard. Inteligência: um conceito reformulado. Ed. Objetiva, RJ, 2001, 348p.

MONTANARI, Tatiana. Histologia: texto, Atlas e roteiro de aulas práticas. Porto Alegre: Editora da UFRGS, 2006. 160 p. 